Research Article

\title{
Coal Burst Induced by Horizontal Section Mining of a Steeply Inclined, Extra-Thick Coal Seam and Its Prevention: A Case Study from Yaojie No. 3 Coal Mine, China
}

\author{
Zhengyi Wang $(\mathbb{D}$, Linming Dou $(\mathbb{D}$, and Guifeng Wang $\mathbb{C}$ \\ Key Laboratory of Deep Coal Resource Mining, Ministry of Education of China, School of Mines, \\ China University of Mining and Technology, Xuzhou 221116, China \\ Correspondence should be addressed to Linming Dou; lmdou@126.com and Guifeng Wang; wgfskl@163.com
}

Received 9 November 2018; Accepted 29 January 2019; Published 26 February 2019

Academic Editor: Vadim V. Silberschmidt

Copyright $(92019$ Zhengyi Wang et al. This is an open access article distributed under the Creative Commons Attribution License, which permits unrestricted use, distribution, and reproduction in any medium, provided the original work is properly cited.

At present, coal bursts in working faces of steeply inclined coal seams (SICSs) have rarely been investigated, and current research focuses on the influences of roof breaking and instability of overlying structures in goaf on coal bursts; however, the stress state of coal masses in working faces being subjected to coal bursts is rarely researched. To overcome the above defects, a model for analysing stresses on coal masses in horizontal section of SICSs was established based on the coal burst that occurred in LW5521-20, Yaojie No. 3 Coal Mine, Lanzhou, Gansu Province, China. Moreover, the mechanism underpinning such a coal burst in SICSs was analysed based on the superposition mechanism of dynamic and static loads. The results show that the side abutment pressure near the roof and floor under the horizontal sections of SICSs is asymmetrically distributed in the vertical direction in which the peak of side abutment pressure near the roof is closer to the working face and therefore is taken as the source of static loads for coal bursts in working faces. When the superimposed dynamic load caused by hanging roof breaking and high static load borne in the coal masses is larger than the critical load for coal burst inception, a coal burst will occur. Furthermore, the superimposed dynamic load induced by coal bursts on the support and the initial static load on the supports are larger than their limiting load, which leads to support collapse and eventually causes dynamic failure of the working face. The coal burst in working faces in horizontal sections of SICSs can be prevented by using deep-hole presplit blasting in a hard roof, destress blasting in coal masses, and support optimisation of working faces, showing a favourable preventative effect.

\section{Introduction}

Steeply inclined coal seams are found in many coal producing areas, such as Xinjiang, Ningxia, Shanxi, Guizhou, Chongqing, Huainan, Gansu, and Beijing [1, 2]. As the major mining area has moved to western China, where half of the mines exploit steeply inclined coal seams, research into the mining of steeply inclined seams has become a high priority [3-5]. In recent years, with the increase of mining depths, coal bursts in steeply inclined, extra-thick coal seams have occurred to the detriment of worker safety and production $[6,7]$.

In terms of dynamic disasters in SICSs, Ju and Li [8] established a mechanical model for a fractured cantilever beam of main roof in SICSs along the inclination direction, and the expression for calculating energies in the cantilever beam was deduced. On this basis, the deep-hole presplit blasting technology for preventing coal bursts was proposed. To control the stability of coal and rock masses in steeply inclined coal roadways, Lai et al. [9] acquired a theoretical basis for the dynamic instability of steeply inclined coal and rock masses through field investigation and theoretical analysis. Furthermore, by utilising various means including numerical calculation, physical model tests, and field monitoring, the spatiotemporal evolutionary characteristics of the instability of steeply inclined coal and rock masses were analysed. By analysing the structural characteristics of coal and rock masses and fracture characteristics of the rocks surrounding the roadway, Wang et al. [10] investigated the distribution and characteristics of zone divisions in fractured 
roadway surrounding rocks in steeply inclined, thick coal seams. Li et al. [11] studied the stability of the roof structure and hydraulic supports with physical simulation and theoretical analysis, which shows that, with increased mining space, the caving angle of the roof strata above the main gate increases. The characteristics of the vertical and horizontal displacement of the roof strata demonstrate that caved blocks rotate around the lower hinged point of the roof structure, which may lead to sliding instability; however, current research into dynamic disasters of SICSs mainly concentrates on coal bursts in roadways while coal bursts in working faces of SICSs have not been of much concern. Additionally, the present research's focus is influences of roof breaking and instability of overlying structures in goaf on coal bursts. While the stress state of coal masses in working faces subjected to coal bursts has not been fully studied and no fairly reliable mechanisms for coal bursts in SICSs has been put forward, to overcome the aforementioned defects, taking the coal burst that occurred in LW5521-20, Yaojie No. 3 Coal Mine as an example, a model for analysing stresses on coal masses in horizontal section of SICSs was established and the mechanism of coal bursts in SICSs was analysed based on the superposition mechanism of dynamic and static loads. Some targeted preventative measures are proposed, which were then applied on site.

\section{Site Description}

2.1. Geological and Mining Conditions. Yaojie No. 3 Coal Mine is one of the main mines of Yaojie Coal Power Group, and the mine field is located in Yaojie town, Honggu District, Lanzhou, Gansu Province, China. The corresponding location map is shown in Figure 1. The No. 2 coal in the No. 5 mining area is the primary mineable coal seam, whose average dip angle and thickness are $60^{\circ}$ and $58.89 \mathrm{~m}$, respectively. The No. 2 coal mine is mined by using fully mechanised caving mining in horizontal sections. Figure 2 shows the mining layout and occurrence of coal seams in the No. 5 mining area. Based on the geological data obtained by drilling and key strata theory [12], the basic conditions of coal and rock strata in the No. 5 mining area are summarized in Table 1.

LW5521-20 is the 20th section $(+1400 \mathrm{~m}$ in the horizontal direction and at $520 \mathrm{~m}$ mining depth) of the No. 5 mining area in Yaojie No. 3 Coal Mine in which the width of the working face, the thickness of the section, mining height, caving height, and mining-caving ratio were $68 \mathrm{~m}, 14.5 \mathrm{~m}$, $2.8 \mathrm{~m}, 11.7 \mathrm{~m}$, and $1: 4.18$, respectively. The belt roadway of the working face is arranged along the roof while the track roadway is arranged along the floor. According to the measured geostresses, the lateral pressure coefficient for the whole coal mine is between 1.5 and 1.8 while that of LW5521-20 was 1.8 owing to the area around of this working face being influenced by the $\mathrm{F}_{607-1}$ fault structure.

2.2. Coal Burst in LW5521-20. A heavy coal burst accident happened in LW5521-20 at 1:48 on 24 March 2016: the miners on site reflected that the tremors were produced from overlying strata. According to results monitored by Lanzhou Earthquake Administration, the magnitude $M_{\mathrm{L}}$ of this "3.24" accident reached 2.4. As shown in Figure 3, the coal burst caused numerous support pillars near the roof in the working face to fail, and support Nos. 1 to 24 collapsed. Moreover, the floor of the belt roadway was uplifted and therefore cracks appeared. All of these factors significantly influenced the safe production of the coal mine.

\section{Mechanism of Coal Bursts Induced by Horizontal Section Mining of SICSs}

3.1. Superposition of Dynamic and Static Loads. A number of studies and field cases have shown that coal bursts are induced by tremors under concentrated stress, i.e., coal bursts induced by dynamic combined with static loads. It can be expressed as $[13,14]$

$$
\sigma_{\mathrm{s}}+\sigma_{\mathrm{d}}>\sigma_{\mathrm{b} \min }
$$

where $\sigma_{\mathrm{s}}$ is the static stress in the coal and rock mass, $\sigma_{\mathrm{d}}$ is the dynamic stress induced by the tremor, and $\sigma_{\mathrm{b} \text { min }}$ is the critical stress required for a coal burst. Equation (1) indicates that the higher the superposition of static load in the coal and dynamic load induced by tremors, the higher the probability that coal bursts will occur.

3.2. Load-Bearing Characteristics of Coal Masses in the SICSs. Many workers $[15,16]$ indicate that the side abutment pressure of coal masses presents a normal distribution along the coal face on the inclination section of SICSs. On this basis, the plane strain model for analysing stresses on SICSs can be established (Figure 4). As shown in Figure 4(a), $\sigma_{\text {sr }}$, $\sigma_{\mathrm{sf}}, \sigma_{\mathrm{sm}}$, and $p_{\mathrm{z}}$ refer to the side abutment pressures near the roof and floor, the peak abutment pressure, and the load (vertically downwards) of overlying strata in goaf on coal masses, respectively. Moreover, a fixed boundary is imposed on the bottom boundary $D E$ of the coal. Additionally, $l_{\mathrm{LW}}, m$, and $\theta$ represent the width of the working face, the thickness, and dip angle of the coal seams, respectively. Figure 4(b) shows the magnified partial detail near the working face in which $l_{A_{1} B_{1}}=l_{C_{1} D_{1}}=6 \mathrm{~m}$ and $l_{B_{1} C_{1}}=56 \mathrm{~m}$.

As shown in Figure 4(a), zone $I$ is mainly subjected to loads from the floor and overlying strata in goaf and it can be thought of as a triangular coal mass owing to it appearing as a right triangle. While zone II mainly suffers from holding stresses from both the roof and floor and therefore can be taken as the load-bearing coal mass. Due to the fact that the stress state in zone I is significantly different from that in zone II, it is necessary to conduct stress analysis on the two zones separately.

3.2.1. Stress State in the Triangular Coal Mass. Figure 5 shows the stress analysis of the triangular coal mass. For convenience in calculation, it is assumed that $A C$ and $B C$ are both the principal stress planes and $A C$ is subjected to uniformly distributed load $\sigma_{1}$ while the stress on $B C$ is relatively complicated. Considering the stress boundary condition, $\sigma_{2}=N_{0}\left(N_{0}\right.$ refers to the supporting stress on the 


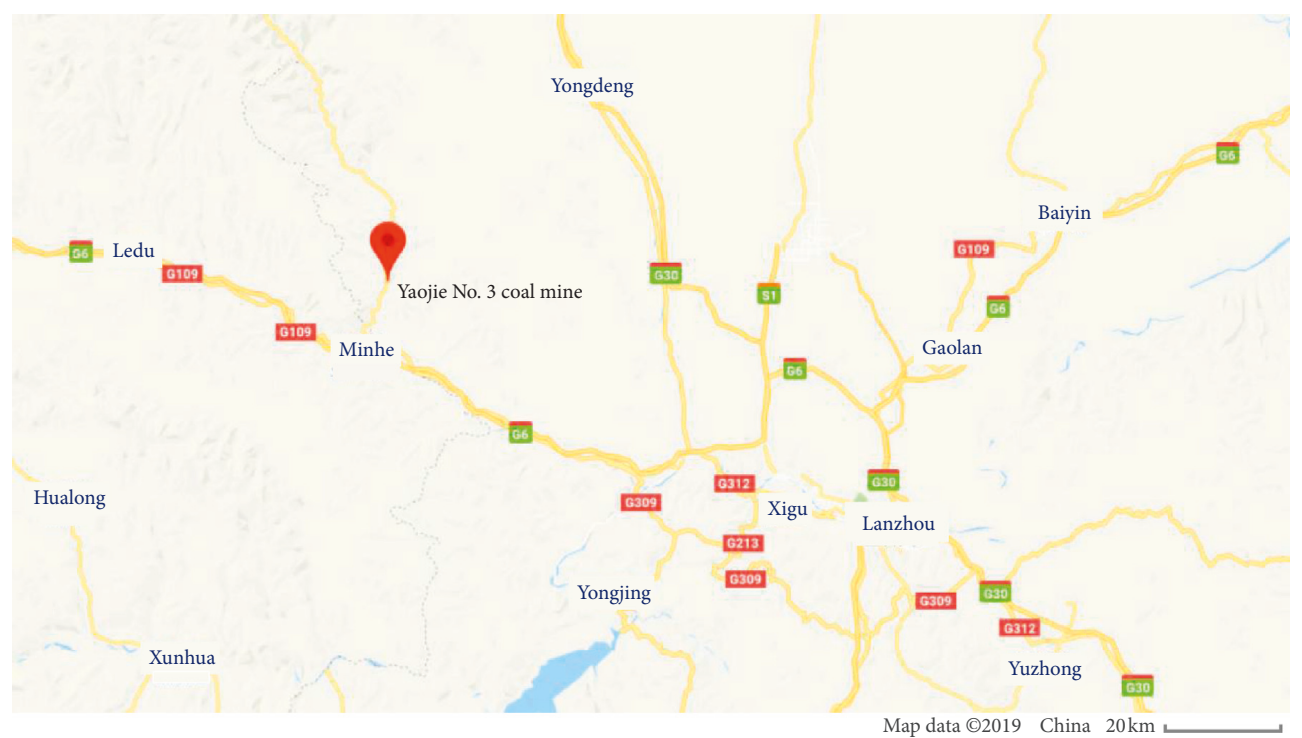

Figure 1: Location map of Yaojie No. 3 Coal Mine.

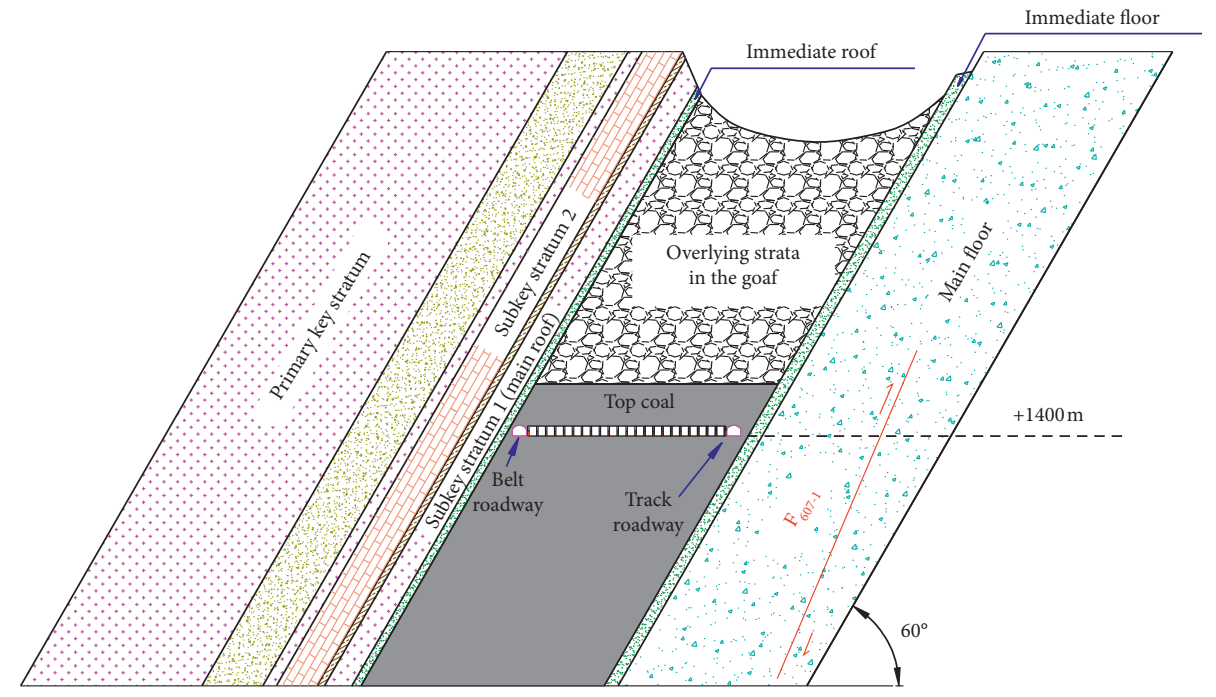

Figure 2: Mining layout and occurrence of coal seams in the No. 5 mining area.

TABLE 1: Basic conditions of coal and rock strata in the No. 5 mining area.

\begin{tabular}{lcc}
\hline Lithology & Thickness $(\mathrm{m})$ & Remarks \\
\hline Oil shale & 43.88 & Primary key stratum \\
Interbedded oil shale and sandstone & 14.77 & \\
Oil shale & 3.33 & Subkey stratum 2 \\
Aluminium mudstone & 9.82 & \\
Carbon mudstone & 1.77 & Subkey stratum $1 /$ main roof \\
Oil shale & 6.68 & Immediate roof \\
Fine sandstone & 2.23 & Primary mineable coal seam \\
No. 2 coal & 58.89 & Immediate floor \\
Coarse sandstone & 3.41 & Main floor \\
Glutenite & 45.73 & .
\end{tabular}

boundary $A C$ of load-bearing coal mass) at point $C$. The static force equilibrium equation of this triangular coal mass is given by

$$
\left\{\begin{array}{l}
\sigma_{1} \cdot m-G_{\mathrm{t}} \sin \theta-F_{\mathrm{z}} \sin \theta=0, \\
F_{B C}-G_{\mathrm{t}} \cos \theta-F_{\mathrm{z}} \cos \theta=0,
\end{array}\right.
$$




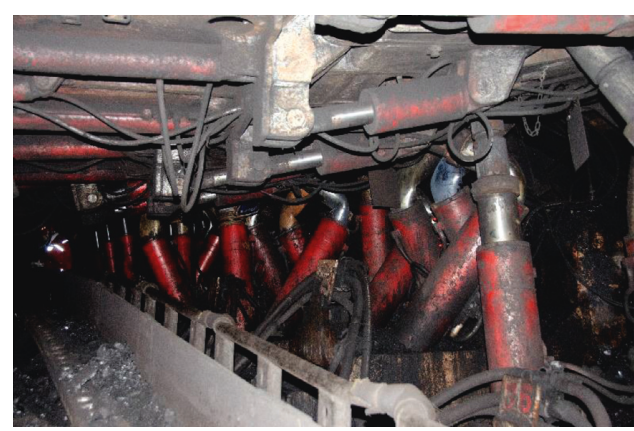

(a)

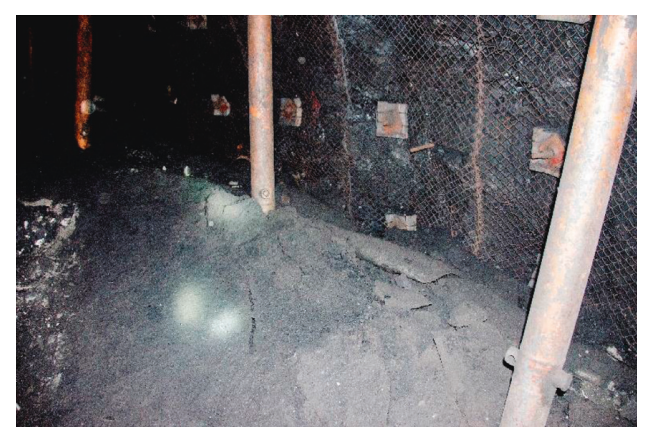

(b)

Figure 3: In situ coal burst failures in LW5521-20. (a) Collapse of hydraulic supports. (b) Floor heave of the belt roadway.

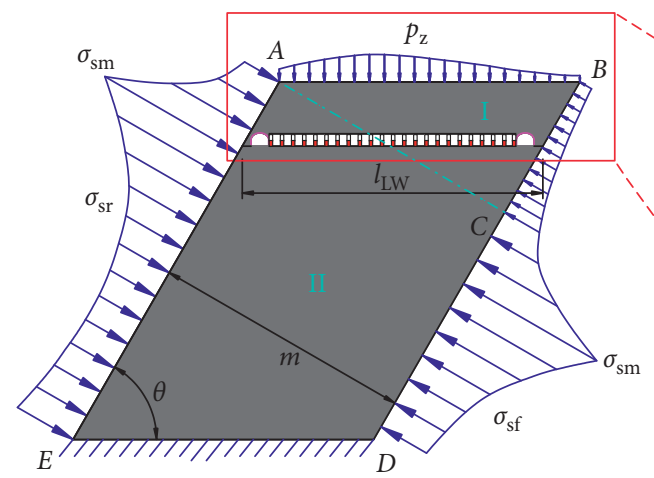

(a)

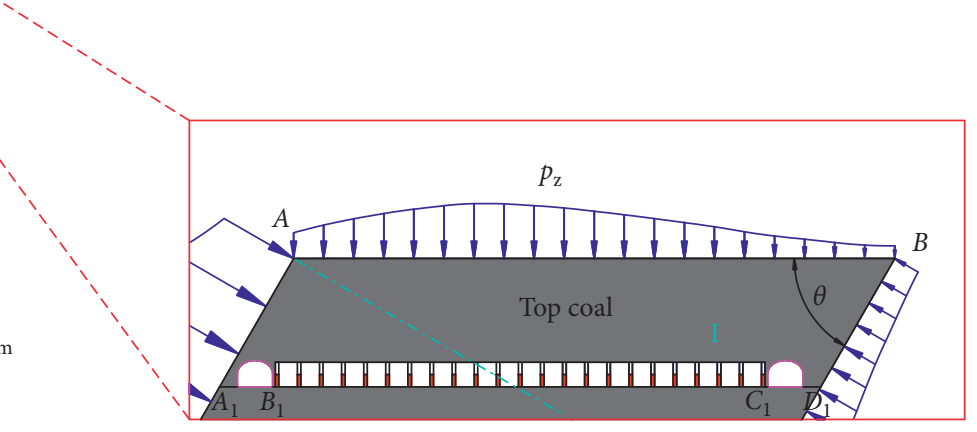

(b)

FIGURE 4: Model for analysing stresses on SICSs. (a) Stress state for a coal mass in a SICS. (b) Magnified partial detail near the working face.

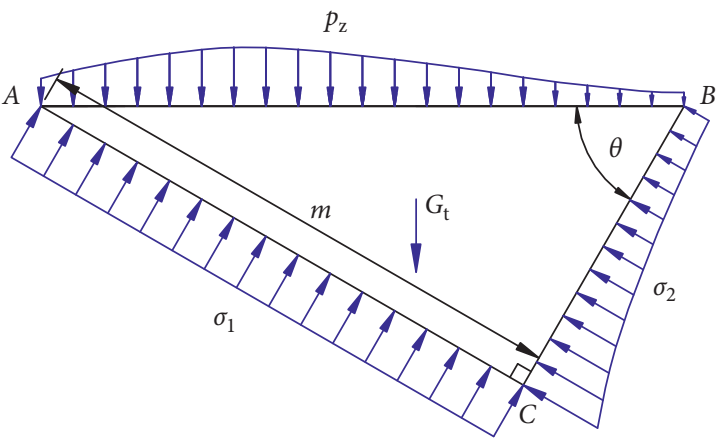

FIGURE 5: Stress analysis of a triangular coal mass.

where $F_{\mathrm{z}}$ refers to the force of overlying strata in goaf on the boundary $A B$ of the coal mass, satisfying $F_{\mathrm{z}}=\int p_{\mathrm{z}} \mathrm{d} l_{A B}$, while $F_{B C}$ denotes the force on the boundary $B C$ near the floor, satisfying $F_{B C}=\int \sigma_{2} \mathrm{~d} l_{B C}$. In addition, $G_{\mathrm{t}}$ represents the self-weight of the triangular coal mass, where $G_{t}=m^{2}$. $\cot \theta \cdot \gamma_{\mathrm{m}}\left(\gamma_{\mathrm{m}}\right.$ refers to the average bulk unit weight $(14 \mathrm{kN} /$ $\mathrm{m}^{3}$ ) of coal masses).

As shown in Figure 4(b), the load $p_{z}$ on the coal mass from overlying strata in the vertical direction is transferred to the working face through the top coal and coal masses near the working face are supported by hydraulic supports. Therefore, the vertical component $F_{\mathrm{v}}$ of force on coal masses near the working face can be approximately expressed as the sum of the force $F_{\mathrm{z}}$ on the coal masses from overlying strata and the self-weight $G_{\mathrm{m}}$ of the top coal, namely,

$$
F_{\mathrm{v}}=F_{\mathrm{z}}+G_{\mathrm{m}},
$$

where $G_{\mathrm{m}}=\gamma_{\mathrm{m}} \cdot l_{\mathrm{LW}} \cdot h_{\mathrm{m}}\left(h_{\mathrm{m}}\right.$ refers to the thickness of the top coal). Moreover, $F_{\mathrm{v}}$ satisfies $F_{\mathrm{v}}=\int p_{\mathrm{v}} \mathrm{d} l_{A_{1} D_{1}}$ ( $p_{\mathrm{v}}$ denotes the vertical component of stresses on coal masses near the working face, which can be deemed approximately equal to the bearing load $p_{\mathrm{s}}$ of hydraulic supports in the working face, namely, $p_{\mathrm{v}}=p_{\mathrm{s}}$ ).

There were 35 pairs of supports (type: ZF4800/17/31, four pillars in a support) in LW5521-20, and the numbers of supports successively increase from the roof to the floor and are numbered 1 to 35 . A pressure gauge was installed at intervals of two pairs of supports to record the load $p_{c}\left(p_{c}\right.$ represents the average load on the pillars of a support) on support pillars. The relationships linking working resistance $f_{\mathrm{s}}$ of supports, bearing loads $p_{\mathrm{s}}$ of supports, and loads $p_{\mathrm{c}}$ on support pillars are given by

$$
\left\{\begin{array}{l}
f_{\mathrm{s}}=4 \cdot p_{\mathrm{c}} \cdot \frac{\pi}{4} d^{2}, \\
p_{\mathrm{s}}=\frac{f_{\mathrm{s}}}{b \cdot L_{\mathrm{kave}}},
\end{array}\right.
$$

where $d, b$, and $L_{\text {kave }}$ refer to the diameter $(0.2 \mathrm{~m})$ of a pillar, the width $(1.6 \mathrm{~m}$, containing $0.1 \mathrm{~m}$ of spacing between 
supports) of supports, and the average roof-control distance (4.44 $\mathrm{m}$ ) of the supports, respectively. Based on equation (4), equation (5) can be obtained and is given by

$$
p_{\mathrm{v}}=p_{\mathrm{s}}=\frac{\pi d^{2}}{b \cdot L_{\mathrm{kave}}} \cdot p_{\mathrm{c}} \text {. }
$$

According to equation (5), the bearing load $p_{\mathrm{s}}$ of corresponding supports can be calculated by using the measured load $p_{c}$ on the support pillars, which can thus give the vertical components $p_{\mathrm{v}}$ of stresses on the coal masses in different locations.

Figure 6 shows the distribution of load $p_{c}$ on support pillars in LW5521-20 near the area where the "3.24" accident occurred and their corresponding vertical components $p_{\mathrm{v}}$ of stresses on coal masses near the working face, where the vertical stresses $\left(p_{\mathrm{v}-\text { roof }}\right.$ and $\left.p_{\mathrm{v} \text {-floor }}\right)$ on the side of the roof and floor can be approximately expressed by using the bearing loads $\left(p_{\mathrm{s} 1}\right.$ and $p_{\mathrm{s} 35}$ ) of the No. 1 and No. 35 supports closest to the roof and floor, respectively, which appear as uniformly distributed loads. The rated pressure $p_{\mathrm{cr}}$ on support pillars is $38 \mathrm{MPa}$. While the relief valve is turned on after reaching $p_{\mathrm{c}}=p_{\mathrm{cr}}$, the support can further bear load until $p_{\mathrm{c}}$ reaches its maximum load $p_{\mathrm{cm}}(60 \mathrm{MPa})$. It can be seen from Figure 6 that the supporting pressures in the middle of LW5521-20 reached their maximum values and were significantly larger than those near the roof and floor. Additionally, the supporting pressures on the side of roof were higher than those on the side of the floor.

Based on the discrete data (Figure 6) of the vertical component $p_{\mathrm{v}}$ of stresses on coal masses near the working face, the vertical component $F_{\mathrm{v}}$ of that force on coal masses near the working face can be approximated by analysing the magnified partial working face (Figure $4(\mathrm{~b})$ ) as given by

$$
\begin{aligned}
F_{\mathrm{v}}= & \int p_{\mathrm{v}} d l_{A_{1} D_{1}}=p_{\mathrm{v}-\text { roof }} \cdot l_{A_{1} B_{1}} \\
& +\sum_{i=1}^{33} \frac{p_{\mathrm{v} i}+p_{\mathrm{v}(i+2)}}{2} \cdot 2 b+p_{\mathrm{v}-\text { floor }} \cdot l_{C_{1} D_{1}},
\end{aligned}
$$

where $p_{\mathrm{v} i}(i=2 n-1,1 \leq n \leq 18)$ refers to the vertical components of stresses on coal masses in different locations where each support of the working face is situated.

The average burial depth $\bar{H}_{B C}$ of the lateral boundary $B C$ of the triangular coal mass on the side of floor is equal to the mining depth (520 m) of LW5521-20 and therefore the mean initial stresses $\bar{\sigma}_{B C}$ on the lateral boundary $B C$ before excavating can be calculated:

$$
\bar{\sigma}_{\mathrm{BC}}=\gamma \bar{H}_{\mathrm{BC}} \cos \theta+\lambda \gamma \bar{H}_{\mathrm{BC}} \sin \theta,
$$

where $\gamma$ refers to the average bulk unit weight $\left(25 \mathrm{kN} / \mathrm{m}^{3}\right)$ of the rock masses and $\lambda$ represents the lateral pressure coefficient (1.8) of LW5521-20.

Therefore, the force $\left[F_{B C}\right]_{\text {ini }}$ on the lateral boundary $B C$ under the initial stress state can be expressed as

$$
\left[F_{B C}\right]_{\text {ini }}=\bar{\sigma}_{B C} \cdot m \cdot \cot \theta .
$$

By substituting the above related parameters and simultaneously calculating equations (2), (3), and (6), $\sigma_{1}=$
$0.78 \mathrm{MPa}$ and $F_{B C}=2.65 \times 10^{7} \mathrm{~N}$ can be obtained. By simultaneously calculating equations (7) and (8), it can be found that $\bar{\sigma}_{B C}=26.77 \mathrm{MPa}$ and $\left[F_{B C}\right]_{\text {ini }}=9.10 \times 10^{8} \mathrm{~N}$. Also, $F_{B C} \ll\left[F_{B C}\right]_{\text {ini }}$, which indicates that the triangular coal mass is already in a limit equilibrium state and the peak mining-induced pressure occurs in the deeper part of loadbearing coal mass.

3.2.2. Abutment Pressure Distribution of Load-Bearing Coal Mass. Figure 7 shows the model used for analysing stresses on the load-bearing coal mass, where $\sigma_{x}$ and $\sigma_{y}$ correspond to the minimum $\sigma_{3}$ and maximum $\sigma_{1}$ principal stresses on coal masses, respectively. Moreover, the stress distributions on the load-bearing coal mass are symmetrical about the $X$ axis.

As shown in Figure $7(\mathrm{a}), \sigma_{\mathrm{sr}}$ and $\sigma_{\text {sf }}$ represent the abutment pressures near the roof and floor of the loadbearing coal mass, respectively, and their corresponding peaks $\sigma_{\text {sm }}$ of abutment pressures are both $K(\gamma H \cos \theta+$ $\lambda \gamma H \sin \theta)(K$ refers to the stress concentration factor and $H$ represents the burial depth).

Figure 7(b) reveals the stress state of load-bearing coal mass in limit equilibrium zone, and the corresponding limit equilibrium equation is given by

$$
m\left(\sigma_{x}+d \sigma_{x}\right)-m \sigma_{x}-2 \sigma_{y} f d x=0,
$$

where $f$ denotes the frictional factor of coal masses with roof and floor, which can be taken as 0.6 [17].

Based on stress conditions in limit equilibrium zone, the corresponding equation is given by

$$
\sigma_{y}=\frac{2 c \cdot \cos \varphi}{1-\sin \varphi}+\frac{1+\sin \varphi}{1-\sin \varphi} \sigma_{x},
$$

where $c$ and $\varphi$ refer to the cohesion and internal frictional angle of coal masses, respectively. According to experimental results, $c=4.2 \mathrm{MPa}$ and $\varphi=34^{\circ}$.

Additionally, when $x=0$, the stress boundary condition of load-bearing coal mass in the limit equilibrium zone can be expressed as

$$
\left\{\begin{array}{l}
\left(\sigma_{x}\right)_{x=0}=\sigma_{1}, \\
\left(\sigma_{y}\right)_{x=0}=N_{0},
\end{array}\right.
$$

where $N_{0}$ denotes the supporting stress on the boundary $A C$ of load-bearing coal mass and is given by

$$
N_{0}=\frac{2 c \cdot \cos \varphi}{1-\sin \varphi}+\frac{1+\sin \varphi}{1-\sin \varphi} \sigma_{1} .
$$

By substituting the value $(0.78 \mathrm{MPa})$ of $\sigma_{1}$ and mechanical parameters of the coal masses into equation (12), it can be found that $N_{0}=18.56 \mathrm{MPa}$.

The equation for $\sigma_{y}$ can be acquired by simultaneously calculating equations (9)-(11) and is given by

$$
\sigma_{y}=N_{0} e^{((2 f x) / m)((1+\sin \varphi) /(1-\sin \varphi))} .
$$

Substituting $\sigma_{y}=\sigma_{\text {sm }}=K(\gamma H \cos \theta+\lambda \gamma H \sin \theta)$ into equation (13), the distance $x_{0}$ to the peak value $\sigma_{\text {sm }}$ of the 


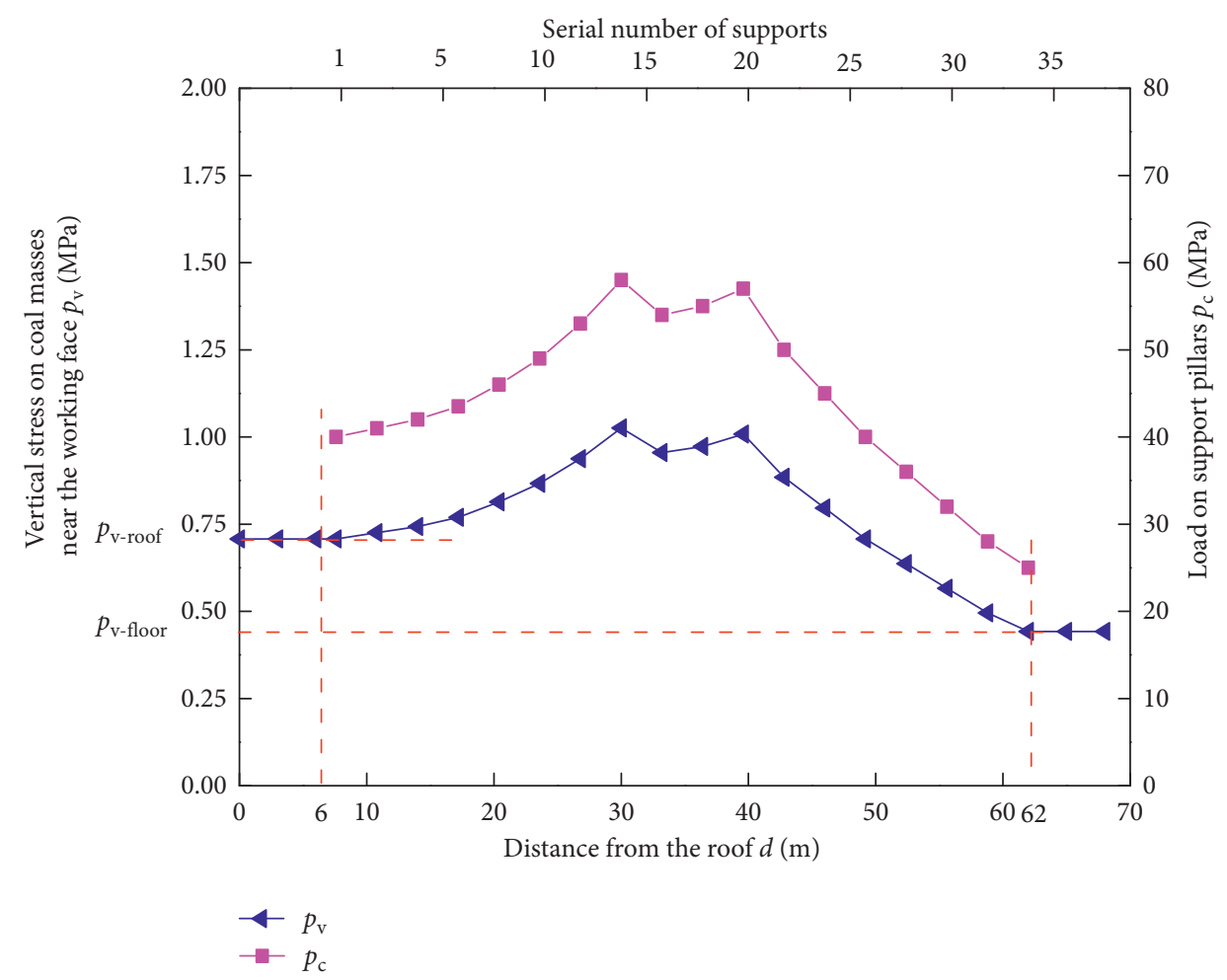

Figure 6: Distribution curves of loads $p_{\mathrm{c}}$ on support pillars near the coal burst area and the corresponding vertical components $p_{\mathrm{v}}$ of stresses on coal masses near the working face.

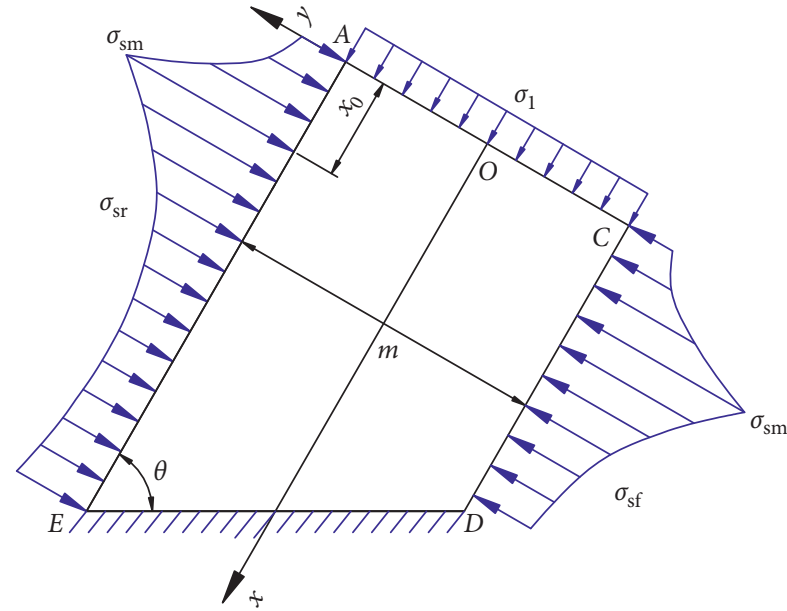

(a)

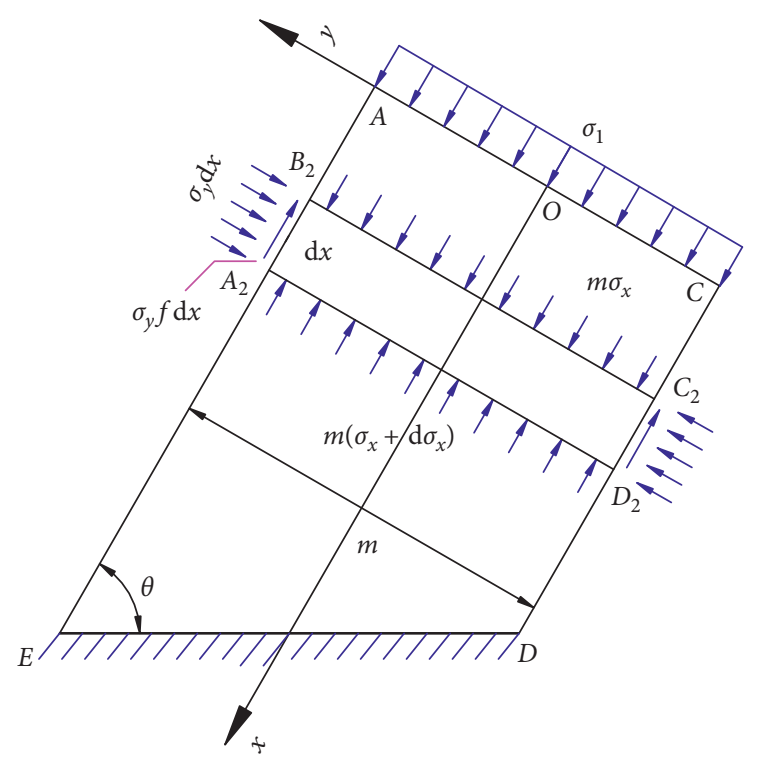

(b)

Figure 7: Model for analysing stresses on load-bearing coal mass. (a) Stress state in the load-bearing coal mass. (b) Stress state in the limit equilibrium zone.

abutment pressure to the boundary $A C$ of load-bearing coal mass is given by

$$
x_{0}=\frac{m}{2 f}\left(\frac{1-\sin \varphi}{1+\sin \varphi}\right) \ln \frac{K(\gamma H \cos \theta+\lambda \gamma H \sin \theta)}{N_{0}},
$$

where the burial depth $H$ varies according to the burial depth (520 m) of LW5521-20. According to existing research results $[18,19]$, the stress concentration factor $K$ of the side abutment pressure of a steeply inclined coal seam ranges from 2.4 to 2.8 and was taken as 2.6 in this study. 
Substituting related parameters into the equation for $\sigma_{\mathrm{sm}}$ and equation (14), it can be found that $\sigma_{\mathrm{sm}}=69.59 \mathrm{MPa}$ and $x_{0}=18.33 \mathrm{~m}$.

It can be seen from the above analysis that the side abutment pressure near the roof and floor under a horizontal section of the SICSs is asymmetrically distributed at the vertical direction in which the peak of side abutment pressure on the side of roof is closer to the working face and therefore it is taken as the source of static load for coal bursts in working faces.

\subsection{Calculation of Dynamic Loads Induced by Microseismic} Events. During the mining of horizontal section of steeply inclined, extra-thick coal seams, the goaf behind the working face in the direction of face advance can provide free space allowing instability of overlying structures in goaf and also key strata fracture. Furthermore, mining-induced microseismic events with high energies are induced by roof breaking, which is considered to be the source of dynamic loads for coal bursts in working faces.

The dynamic loads of P- and S-waves caused by microseismic events can be calculated [20] by

$$
\left\{\begin{array}{l}
\sigma_{\mathrm{dP}}=\rho C_{\mathrm{P}} v_{\mathrm{pp}}, \\
\sigma_{\mathrm{dS}}=\rho C_{\mathrm{S}} v_{\mathrm{ps}}
\end{array}\right.
$$

where $\sigma_{\mathrm{dP}}, \sigma_{\mathrm{dS}}, \rho, C_{\mathrm{P}}, C_{\mathrm{S}}, v_{\mathrm{pp}}$, and $v_{\mathrm{ps}}$ refer to the dynamic loads induced by $\mathrm{P}$ - and S-waves, density of media, propagation speeds of $\mathrm{P}$ - and $\mathrm{S}$-waves, and particle vibration velocities of $\mathrm{P}$ - and S-waves, respectively.

Based on the in situ experiment to assess propagation of tremor waves in underground mines [21], the attenuation of the peak velocity of tremor waves is given by:

$$
v_{\mathrm{p}}\left(l_{\mathrm{d}}\right)=v_{\mathrm{pm}} l_{\mathrm{d}}^{-1.526},
$$

where $l_{\mathrm{d}}, v_{\mathrm{pm}}$, and $v_{\mathrm{p}}\left(l_{\mathrm{d}}\right)$ denote the propagation distance of the tremor waves, the peak particle vibration velocity, and the particle vibration velocity at a distance $l_{\mathrm{d}}$ from the microseismic source, respectively.

Cao et al. [22] showed that the amplitude of S-waves radiated from microseismic events with high energies is far larger than that of $\mathrm{P}$-waves, and the former shows a stronger dynamic failure strength. Therefore, the S-wave is applied here. By simultaneously calculating equations (15) and (16), the dynamic load produced by S-waves from microseismic events can be expressed as

$$
\sigma_{\mathrm{dS}}\left(l_{\mathrm{d}}\right)=\rho C_{\mathrm{S}} v_{\mathrm{psm}} \cdot l_{\mathrm{d}}^{-1.526},
$$

where $v_{\mathrm{ps} m}$ and $\sigma_{\mathrm{dS}}\left(l_{\mathrm{d}}\right)$ represent the peak of particle vibration velocity of $S$-waves and the dynamic load produced by the $S$-waves at distance $l_{\mathrm{d}}$ from the microseismic event source, respectively.

3.4. Critical Stress of Coal Bursts. Numerous studies show that the critical stress of coal bursts is related to the uniaxial compressive strength of coal $[23,24]$ as shown in Figure 8. When the uniaxial compressive strength is less than $16 \mathrm{MPa}$,

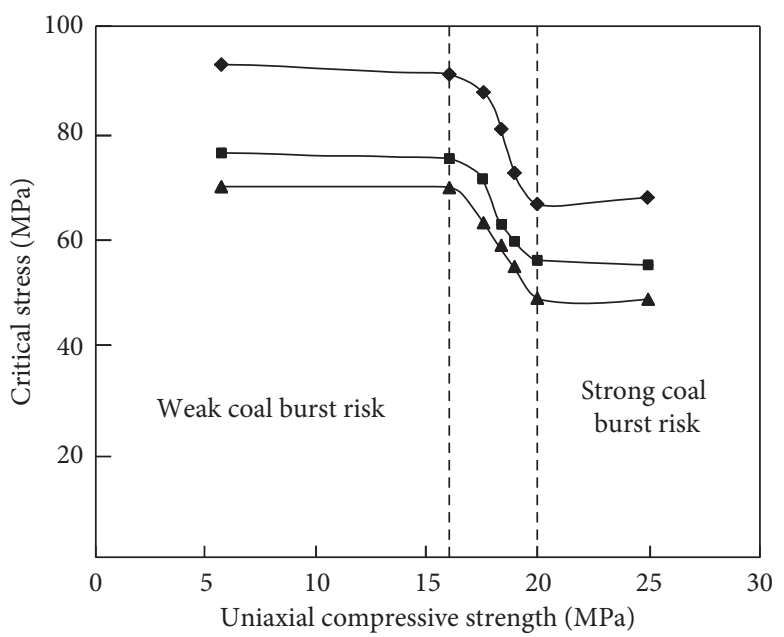

FIGURE 8: Relationship between critical stress of coal burst and uniaxial compressive strength of coal.

the critical stress is $70 \mathrm{MPa}$, and when the uniaxial compressive strength is greater than $20 \mathrm{MPa}$, the critical stress reduces to $50 \mathrm{MPa}$. The mean compressive strength for the tests conducted for identifying coal burst tendencies is about $13.1 \mathrm{MPa}$. Therefore, the critical stress $\sigma_{\mathrm{b} \text { min }}$ of LW5521-20 is $70 \mathrm{MPa}$.

3.5. Case Study. Based on the superposition mechanism of dynamic and static loads, the mechanism of coal bursts in the working faces of SICSs was analysed by taking the "3.24" coal burst accident in LW5521-20, Yaojie No. 3 Coal Mine as an example.

Figure 9 shows the schematic diagram of coal bursts in LW5521-20: the dynamic load $\sigma_{\mathrm{d}}$ caused by overlying strata breaking is superimposed on the static load (abutment pressures) of coal masses and thus the position with the peak abutment pressure $\sigma_{\mathrm{sm}}$ is the most likely to undergo coal bursting, which is regarded as the key research object for coal bursts. When the superimposed stress $\left(\sigma_{\mathrm{sm}}+\sigma_{\mathrm{d}}\right)$ at the position with the highest abutment pressure is larger than the critical stress $\sigma_{\mathrm{b} \text { min }}(70 \mathrm{MPa}$ ) for coal bursts, a coal burst will occur in the interior of coal masses and then the fractured zone ( $l_{\mathrm{cb}}$ refers to the length of the fractured zone) induced by coal bursts will appear accordingly, which is shown as the red rectangle in Figure 9. Moreover, the "3.24" accident was caused by the large-energy microseismic event $\left(M_{\mathrm{L}}=2.4\right)$ from the overlying strata, and it can be seen that the corresponding energy $E_{\mathrm{d} 0}$ released by this " 3.24 " accident is $2.29 \times 10^{6} \mathrm{~J}$, based on the existing empirical equation [25] $\log E_{\mathrm{d} 0}=1.8+1.9 M_{\mathrm{L}}$ relating the energy $E_{\mathrm{d} 0}$ and magnitude $M_{\mathrm{L}}$.

The SOS microseismic monitoring system (the SOS system was installed and put into effect on 8 November 2016) had not been installed in the Yaojie No. 3 Coal Mine during the "3.24" accident; therefore, the location of the microseismic event causing the "3.24" accident cannot be precisely obtained; however, the locations where highenergy microseismic events occurred can be found from 


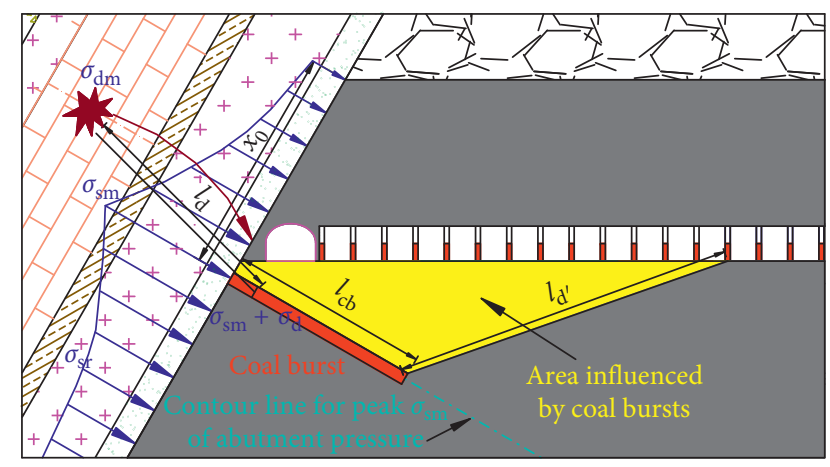

FIGURE 9: Schematic diagram of coal burst in LW5521-20.

the locations of microseismic events recorded after installing the SOS system, in the same working face (LW5521-20). Figure 10 shows the profile of microseismic event locations of LW5521-20 (from 10 to 30 November 2016). It can be seen from Figure 10 that the high-energy microseismic events with $10^{5}$ to $10^{6} \mathrm{~J}$ (microseismic energies decreased after taking preventative measures) mainly occurred within the aluminium mudstone (subkey stratum 2) within the range $(13.4 \mathrm{~m}$ to $15.8 \mathrm{~m})$ of vertical distance from the left sidewall of the belt roadway. On this basis, the position having the average vertical distance of $14.6 \mathrm{~m}$ from the left sidewall of the belt roadway can be approximately taken as the location for the microseismic event $\left(2.29 \times 10^{6} \mathrm{~J}\right)$ inducing the " 3.24 " accident. Namely, the subkey stratum 2 reaching its limiting length of hanging roof was fractured under the influence of coal mining, and then the high-energy microseismic event $\left(2.29 \times 10^{6} \mathrm{~J}\right)$ was induced accordingly.

$\mathrm{He}$ et al. [21] showed that for a peak particle vibration velocity (of the S-waves) of $10^{6} \mathrm{~J}$ to $10^{7} \mathrm{~J}$ events can be up to $12.17 \mathrm{~m} / \mathrm{s}$. Taking the density of the medium (aluminium mudstone) at the microseismic source as $2,500 \mathrm{~kg} / \mathrm{m}^{3}$ and propagation speed of $\mathrm{S}$-waves as $2,480 \mathrm{~m} / \mathrm{s}$, the expression of $\sigma_{\mathrm{dS}}\left(l_{\mathrm{d}}\right)$ with $10^{6} \mathrm{~J}$ to $10^{7} \mathrm{~J}$ can be obtained by substituting these parameters into equation (17); however, the static stress $\sigma_{\text {sm }}$ can be up to $69.59 \mathrm{MPa}$ according to the contour line for peak abutment pressures. Based on the mechanism of coal bursts induced by dynamic load combined with static load, when $\sigma_{\mathrm{sm}}+\sigma_{\mathrm{dS}}\left(l_{\mathrm{d}}\right)>70 \mathrm{MPa}$, the coal burst will occur and zones satisfying the coal burst criterion all belong to fractured zones in the contour line of peak of abutment pressures. According to the above parameters, the corresponding calculation results are obtained. The superimposed stress $\left(\sigma_{\mathrm{sm}}+\sigma_{\mathrm{d}}\right)$ of the dynamic stress $\sigma_{\mathrm{d}}$ propagating to the contour line for the peak abutment pressure, and the peak abutment pressure itself, all meet the coal burst criterion when the propagation distance $l_{\mathrm{d}}$ of tremor waves is less than $30.66 \mathrm{~m}$ and the corresponding length $l_{\mathrm{cb}}$ of fractured zone induced by coal bursts is $16.06 \mathrm{~m}$ (based on the previously determined location of the microseismic source for the "3.24" accident and the relative location relationship between the working face and overlying strata, an auxiliary circle can be drawn in Figure 9 by taking the location of the microseismic source as the centre and $l_{\mathrm{d}}(30.66 \mathrm{~m})$ as the radius, which then intersected the contour line for $\sigma_{\mathrm{sm}}$; in this way, the value of $l_{\mathrm{cb}}$ can be acquired).

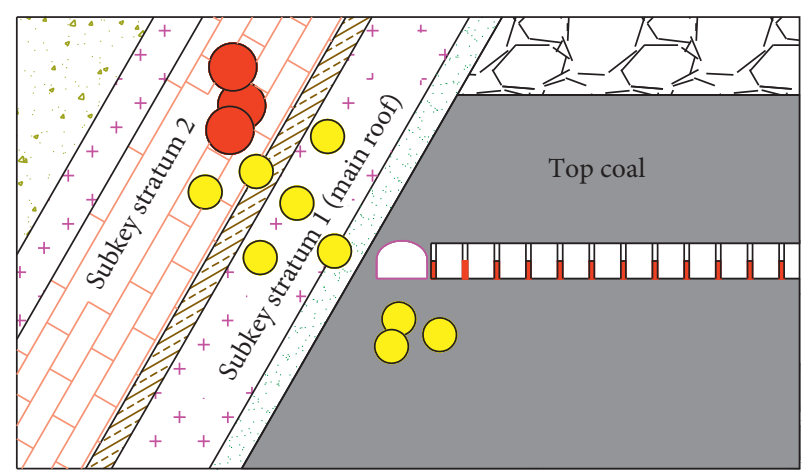

$$
\begin{aligned}
& \bigcirc E_{\mathrm{d} 0}: 10^{5} \sim 10^{6} \mathrm{~J} \\
& E_{\mathrm{d} 0}: 10^{4} \sim 10^{5} \mathrm{~J}
\end{aligned}
$$

Figure 10: Profile of microseism locations of LW5521-20 (from 10 to 30 November 2016).

Moreover, tremor waves can also be caused by coal bursts in working faces. Microseismic monitoring results (Figure 10) reveal that microseismic events also occurred in the interior of coal masses of working faces with a stable energy of $10^{4}$ to $10^{5} \mathrm{~J}$. On this basis, it can be speculated that the microseismic energy caused by the coal burst in the "3.24" accident is at least in the range of $10^{4}$ to $10^{5} \mathrm{~J}$. He et al. [21] showed that the peak particle vibration velocity (S-wave) with energies of $10^{4}$ to $10^{5} \mathrm{~J}$ can be up to $3.5 \mathrm{~m} / \mathrm{s}$. Although the microseismic energy caused by overlying strata breaking is larger than that induced by coal bursts, the former can be attenuated sufficiently (microseismic energy attenuates as a power function with the propagation distance (equation (17)) when propagating to hydraulic supports in working faces owing to it being far from LW5521-20). The failure of supports in LW5521-20 is mainly influenced by microseismic events (closer to LW5521-20) induced by coal bursts.

To calculate additional dynamic loads induced by coal bursts on hydraulic supports, it can be considered that microseismic energies at any position in the fractured zone of coal bursts are all in the range of $10^{4}$ to $10^{5} \mathrm{~J}$. In Figure 9, the minimum distances of the fractured zone to various supports were successively measured as the propagation distances $l_{\mathrm{d}}^{\prime}$ of dynamic loads caused by coal bursts. In addition, the peak particle vibration velocity (S-wave), the density of the medium (coal masses) at the microseismic source, and the propagation speed of S-waves are taken as $3.5 \mathrm{~m} / \mathrm{s}, \quad 1,400 \mathrm{~kg} / \mathrm{m}^{3}$, and $2,480 \mathrm{~m} / \mathrm{s}$, respectively. By substituting these parameters into equation (17), the additional dynamic loads $\Delta \sigma_{\mathrm{dS}}\left(l_{\mathrm{d}}^{\prime}\right)$ induced by coal bursts on various hydraulic supports can be obtained.

Based on equation (5), additional loads $\Delta p_{\mathrm{s}}$ required by various supports before dynamic failure can be expressed as

$$
\Delta p_{\mathrm{s}}=\frac{\pi d^{2}}{b \cdot L_{\mathrm{kave}}} \cdot \Delta p_{\mathrm{c}}
$$

where $\Delta p_{\mathrm{c}}$ refers to additional loads required for failures of support pillars, meeting $\Delta p_{\mathrm{c}}=p_{\mathrm{cm}}-p_{\mathrm{c}}$. In addition, $p_{\mathrm{m}}$ represents the maximum load (60 $\mathrm{MPa})$ on support pillars 
and $p_{c}$ refers to the in situ measured discrete data pertaining to loads on support pillars in Figure 6.

Figure 11 shows distribution curves of additional loads $\Delta p_{\mathrm{s}}$ required for failures of supports, additional dynamic loads $\Delta \sigma_{\mathrm{ds}}$ induced by coal bursts on various hydraulic supports, and the differences $\left(\Delta \sigma_{\mathrm{dS}}-\Delta p_{\mathrm{s}}\right)$ between these two parameters. It can be seen from Figure 11 that the additional loads induced by coal bursts on support Nos. 1 to 21 were all larger than those required for failure of the supports, causing them to collapse (while the rest of supports remained in good condition). By contrast, actually support Nos. 1 to 24 were fractured (while the rest of supports were in good conditions) in the "3.24" accident, which was due to the fact that only the coal burst at the position with the peak of abutment pressures was analysed in the theoretical calculation while its neighbouring areas can also be subjected to coal bursts in practice. As a result, the higher energy $\left(>10^{4} \mathrm{~J}\right)$ of microseismic events can be induced by the larger damaged area and then more supports may collapse. The theoretical analysis was basically consistent with the observed in situ damage caused by actual coal bursts. It is owing to the location with peak abutment pressures on the side of roof for SICSs being closer to LW5521-20 that the coal burst has a more serious influence on the working face near the roof, namely, the supports in the vicinity of roof are severely damaged.

As for the belt roadway, the coal mass of roadway floor is hard without being supported, and the horizontal tectonic stress is relatively large (the lateral pressure coefficient reaches 1.8). In addition, vertical stresses on the rock surrounding the roadway decrease significantly due to the mining-out of the top of the coal masses. All of these mean that the coal mass of the roadway floor exhibits a high static load stress concentration (a large difference between the maximum and minimum principal stresses). When the superimposed stresses of additional dynamic loads induced by coal bursts and high static stresses in coal masses of the roadway floor satisfy the coal burst criterion, dynamic failure of the roadway floor will occur.

\section{Preventative Measures and Tests of Their Efficacy}

To prevent coal bursts in LW5521-20, based on the mechanism of coal bursts induced by dynamic and static loads and intensity weakening theory for coal bursts [26, 27], preventative measures can be viewed in three ways: (1) decreasing the strengths of static stresses on coal masses in working faces and dynamic stresses induced by microseismic events; (2) weakening the intensity of areas influenced by coal bursts; and (3) optimising supporting parameters in working faces.

4.1. Deep-Hole Presplit Blasting in a Hard Roof. The long hanging roof formed in overlying strata of the SICSs is an important factor for coal bursts [8]. Zhu [28] indicates that loads on hanging roofs in the goaf can be transferred to coal masses in the working faces under the influence of mining. The longer the lengths $L_{\mathrm{h}}$ of hanging roof, the more loads are

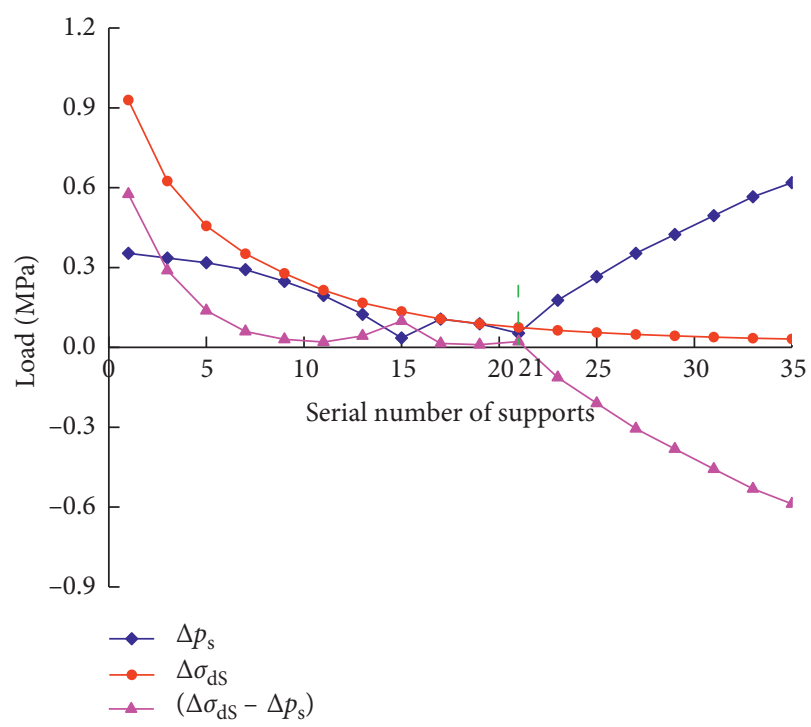

Figure 11: Distribution curves of additional loads $\Delta p_{\mathrm{s}}$ required by failures of supports, additional dynamic loads $\Delta \sigma_{\mathrm{ds}}$ induced from coal bursts on hydraulic supports, and difference values $\left(\Delta \sigma_{\mathrm{ds}}\right.$ $\left.-\Delta p_{s}\right)$.

transferred from hanging roofs and the larger stress concentration factors $K$ of side bearing pressure of coal masses, namely, the higher the static stresses $\sigma_{\mathrm{s}}$ acting on a coal mass. Additionally, elastic energies $E_{\mathrm{e}}$ accumulated in hanging roofs are such that $E_{\mathrm{e}} \propto L_{\mathrm{h}}^{5}$ [8] while about $0.1 \%$ to $1 \%$ of $E_{\mathrm{e}}$ is transformed into microseismic energy $E_{\mathrm{d} 0}$ [29], which means that the longer the length $L_{\mathrm{h}}$ of hanging roofs, the greater the elastic energies $E_{\mathrm{e}}$ accumulated in the roof and the greater the microseismic energy $E_{\mathrm{d} 0}$ released during roof breaking (and the stronger the dynamic stresses $\sigma_{\mathrm{d}}$ are on the coal masses). Based on the aforementioned analysis, it is necessary to shorten the lengths of hanging roofs by using deep-hole presplit blasting, and then static stresses $\sigma_{\mathrm{s}}$ on coal masses in working faces and dynamic stresses $\sigma_{\mathrm{d}}$ induced by microseismic events can both be effectively decreased.

Figure 12 shows the profile of deep-hole presplit blasting in a hard roof. Measures were taken within 30 to $150 \mathrm{~m}$ from the advanced working face during recovery operations following the " 3.24 " accident, while measures were taken at least $150 \mathrm{~m}$ from the advanced working face during normal mining. The preliminary design parameters of $1 \# \sim 3 \#$ blasting holes are shown in Table 2.

The SOS monitoring results showed that $10^{5}$ to $10^{6} \mathrm{~J}$ microseismic events still occurred in the roof after taking preliminary measures involving deep-hole presplit blasting. Therefore, to achieve a favourable preventative effect, the blasting parameters have been optimised by increasing the explosive charge since 24 March 2017. The optimised design parameters are shown in Table 3.

4.2. Destress Blasting in Coal Masses. To guarantee the safety of working face and roadways, the strength and degree of stress concentration in coal masses can be reduced by implementing destress blasting on areas influenced by coal bursts, which can 


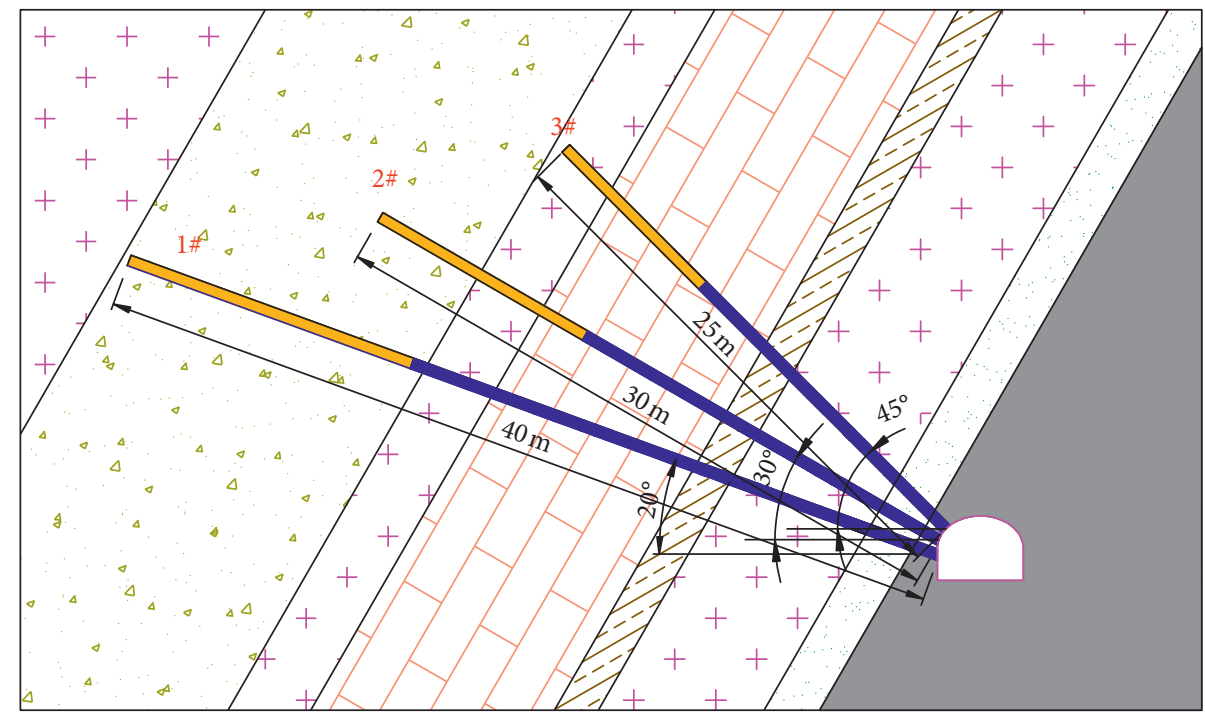

Figure 12: Profile of deep-hole presplit blasting in a hard roof.

TABle 2: Preliminary design parameters for deep-hole presplit blasting.

\begin{tabular}{|c|c|c|c|c|c|c|c|c|}
\hline $\begin{array}{l}\text { Blasting } \\
\text { agent }\end{array}$ & Number & $\begin{array}{c}\text { Angle } \\
\left({ }^{\circ}\right)\end{array}$ & $\begin{array}{c}\text { Length of } \\
\text { borehole }(\mathrm{m})\end{array}$ & $\begin{array}{c}\text { Diameter of } \\
\text { borehole }(\mathrm{mm})\end{array}$ & $\begin{array}{c}\text { Distance between } \\
\text { boreholes }(\mathrm{m})\end{array}$ & $\begin{array}{l}\text { Stemming } \\
\text { length }(\mathrm{m})\end{array}$ & $\begin{array}{c}\text { Explosive charge } \\
\text { length }(\mathrm{m})\end{array}$ & $\begin{array}{c}\text { Explosive charge } \\
\text { weight }(\mathrm{kg})\end{array}$ \\
\hline \multirow{3}{*}{$\begin{array}{l}\text { Emulsion } \\
\text { explosive }\end{array}$} & $1 \#$ & 20 & 40 & 75 & 10 & 28 & 12 & 29 \\
\hline & $2 \#$ & 30 & 30 & 75 & 10 & 20 & 10 & 24 \\
\hline & $3 \#$ & 45 & 25 & 75 & 10 & 17 & 8 & 20 \\
\hline
\end{tabular}

TABLE 3: Optimised design parameters for deep-hole presplit blasting.

\begin{tabular}{|c|c|c|c|c|c|c|c|c|}
\hline $\begin{array}{l}\text { Blasting } \\
\text { agent }\end{array}$ & Number & $\begin{array}{c}\text { Angle } \\
\left({ }^{\circ}\right)\end{array}$ & $\begin{array}{c}\text { Length of } \\
\text { borehole }(\mathrm{m})\end{array}$ & $\begin{array}{c}\text { Diameter of } \\
\text { borehole }(\mathrm{mm})\end{array}$ & $\begin{array}{c}\text { Distance between } \\
\text { boreholes }(\mathrm{m})\end{array}$ & $\begin{array}{l}\text { Stemming } \\
\text { length }(\mathrm{m})\end{array}$ & $\begin{array}{c}\text { Explosive charge } \\
\text { length }(\mathrm{m})\end{array}$ & $\begin{array}{c}\text { Explosive charge } \\
\text { weight }(\mathrm{kg})\end{array}$ \\
\hline \multirow{3}{*}{$\begin{array}{l}\text { Emulsion } \\
\text { explosive }\end{array}$} & $1 \#$ & 20 & 40 & 75 & 10 & 25 & 15 & 58 \\
\hline & $2 \#$ & 30 & 30 & 75 & 10 & 17 & 13 & 50 \\
\hline & $3 \#$ & 45 & 25 & 75 & 10 & 15 & 10 & 38 \\
\hline
\end{tabular}

lead to high static stresses being transferred to deeper coal masses. Due to the fact that the location of the peak abutment pressure on the side of roof is closer to the working face, destress blasting should be applied in the belt roadway.

Figure 13 shows the profile of destress blasting in such coal masses. The positions of destress blasting are the same as those of deep-hole presplit blasting during the recovery operations undertaken after the " 3.24 " accident and during normal mining. The design parameters of $4 \# \sim 7 \#$ blasting holes are shown in Table 4.

4.3. Optimum Design of Supports in Working Faces. It can be seen from Figure 6 that some loads $p_{c}$ on support pillars can be approximately equal to the limiting load $p_{\mathrm{cm}}$ during the mining period, and these supports are also influenced by dynamic loads $\sigma_{\mathrm{d}}$ induced by roof breaking. The rated resistance $f_{\text {s-rated }}$ of current supports is $4,800 \mathrm{kN}$ while the maximum additional dynamic load, induced by coal bursts, on the supports is $0.93 \mathrm{MPa}$ through aforementioned case study analysis (Figure 11). Namely, the maximum additional load $p_{\text {s-add }}$ of supports required for resisting dynamic loads is $0.93 \mathrm{MPa}$. By substituting $p_{\text {s-add }}$ into equation (4), the required additional resistance for the supports is $6,603 \mathrm{kN}$. Therefore, the total resistance $f_{\text {s-total }}$ of supports for resisting the dynamic and static loads should be $11,403 \mathrm{kN}$ $\left(f_{\text {s-total }}=f_{\text {s-rated }}+f_{\text {s-add }}\right)$. For the safety of mining and convenient selection of supporting parameters, the rated resistance of hydraulic supports can be identified as being $12,000 \mathrm{kN}$.

4.4. Tests of the Efficacy of the Preventative Measures. During the recovery of LW5521-20 after the "3.24" accident, preventative measures were tested by using the method of drilling bits in the belt roadway. The corresponding parameters of drilling holes are as follows: the drilling holes were arranged at intervals of $20 \mathrm{~m}$ beginning from a location some $5 \mathrm{~m}$ from the advanced working face, to a point $60 \mathrm{~m}$ from the advanced working face. Monitoring results of the method of drilling bits during the recovery of LW5521-20 are shown in Figure 14. The results measured on 26 March 2016 represent drilling cutting weights before taking preventative measures, where coal weights in most positions of 


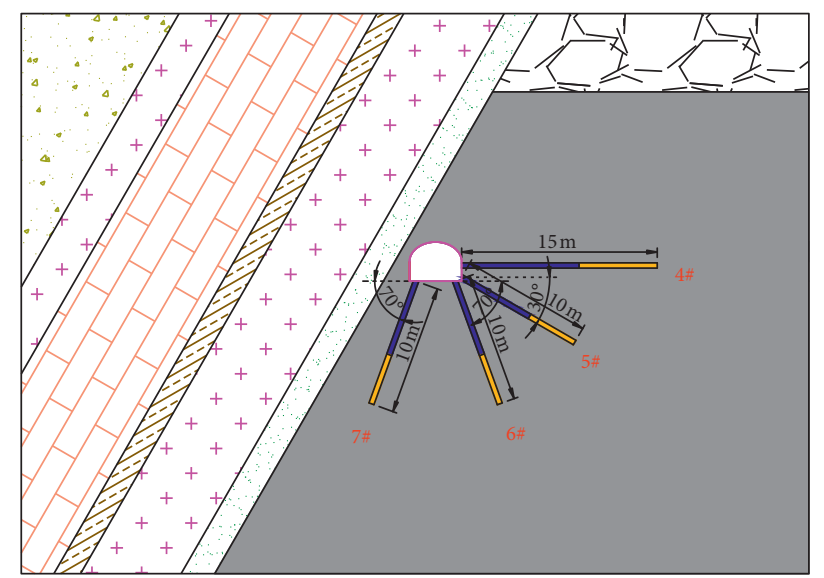

Figure 13: Profile of destress blasting in coal masses.

TABLE 4: Design parameters for destress blasting in coal masses.

\begin{tabular}{lcccccccc}
\hline $\begin{array}{l}\text { Blasting } \\
\text { agent }\end{array}$ & Number & $\begin{array}{c}\text { Angle } \\
\left({ }^{\circ}\right)\end{array}$ & $\begin{array}{c}\text { Length of } \\
\text { borehole }(\mathrm{m})\end{array}$ & $\begin{array}{c}\text { Diameter of } \\
\text { borehole }(\mathrm{mm})\end{array}$ & $\begin{array}{c}\text { Distance between } \\
\text { boreholes }(\mathrm{m})\end{array}$ & $\begin{array}{c}\text { Stemming } \\
\text { length }(\mathrm{m})\end{array}$ & $\begin{array}{c}\text { Explosive charge } \\
\text { length }(\mathrm{m})\end{array}$ & $\begin{array}{c}\text { Explosive charge } \\
\text { weight }(\mathrm{kg})\end{array}$ \\
\hline \multirow{3}{*}{ Emulsion } & $4 \#$ & 0 & 15 & 42 & 5 & 5 & 7 & 7 \\
explosive & $5 \#$ & 30 & 10 & 42 & 5 & 5 & 5 & 5 \\
& $7 \#$ & 70 & 10 & 42 & 5 & 5 & 5 & 5 \\
\hline
\end{tabular}

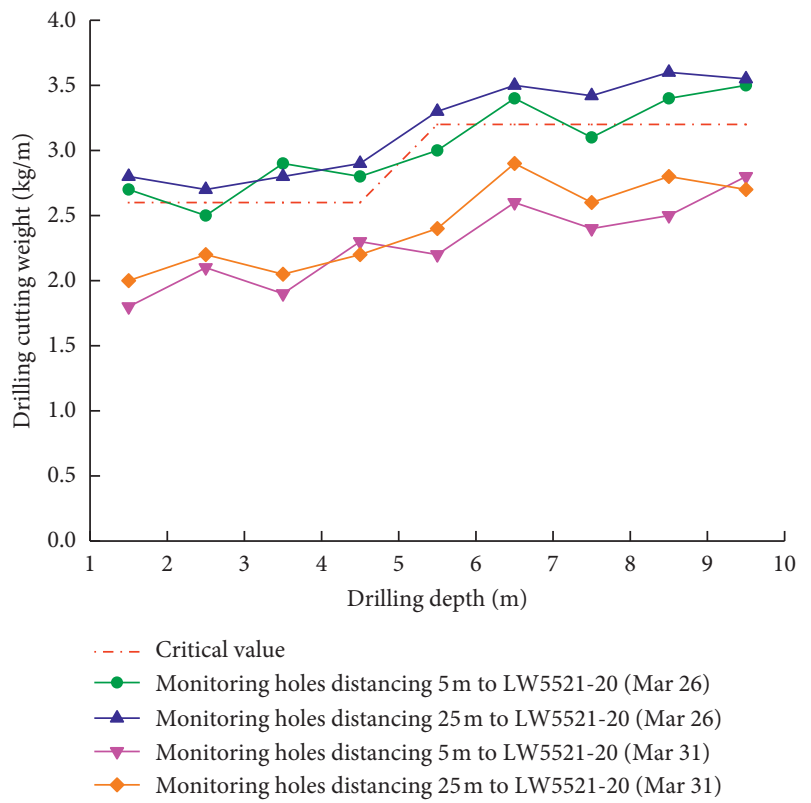

FIGURE 14: Monitoring results: drilling cutting weights during the recovery of LW5521-20.

monitored holes at $5 \mathrm{~m}$ and $25 \mathrm{~m}$ from the working face were larger than the critical value of drilling cutting weight; however, the results acquired on 31 March 2016 denote drilling cutting weights after taking preventative measures and those in all monitored holes at $5 \mathrm{~m}$ and $25 \mathrm{~m}$ from the working face were all below the critical value. These results show that preventative measures can decrease the risk of coal bursts in working faces and roadways.
Figure 15 shows microseismic monitoring results after the parameter optimisation of deep-hole presplit blasting; from 25 March 2017 to 1 April 2017, the data refer to the initial stage of optimisation, during which the total microseismic energies were high. This is because preventative effects at this initial stage of optimisation had not yet fully appeared. Moreover, from 2 April 2017 to 17 April 2017, the works entered the middle stage of optimisation, during which microseismic frequencies significantly increased while the total microseismic energies decreased to some extent. This indicates that fractures in overlying strata were fully developed in this stage and therefore strengths of overlying strata decreased, causing microseismic events with low energies to recur frequently; this reflects the significant preventative effect of the aforementioned optimisation. In addition, the final stage of the optimisation lasted from 18 April 2017 to 25 April 2017; in this stage, the total microseismic energies and microseismic frequencies both greatly decreased, which demonstrated that elastic energies accumulated in hanging roofs are released and therefore the risk of coal bursts on the working face has been relieved.

Furthermore, there has been no coal burst in LW5521-20 since (or in its roadways) after taking such preventative measures, which implies that coal bursts in working faces of SICSs can be effectively prevented by using deep-hole presplit blasting, destress blasting in coal masses, and parameter optimisation in the design of hydraulic supports.

\section{Conclusions}

(1) Based on the stress state of coal masses for horizontal sections in SICSs, the steeply inclined coal mass is divided into the triangular and load-bearing coal 


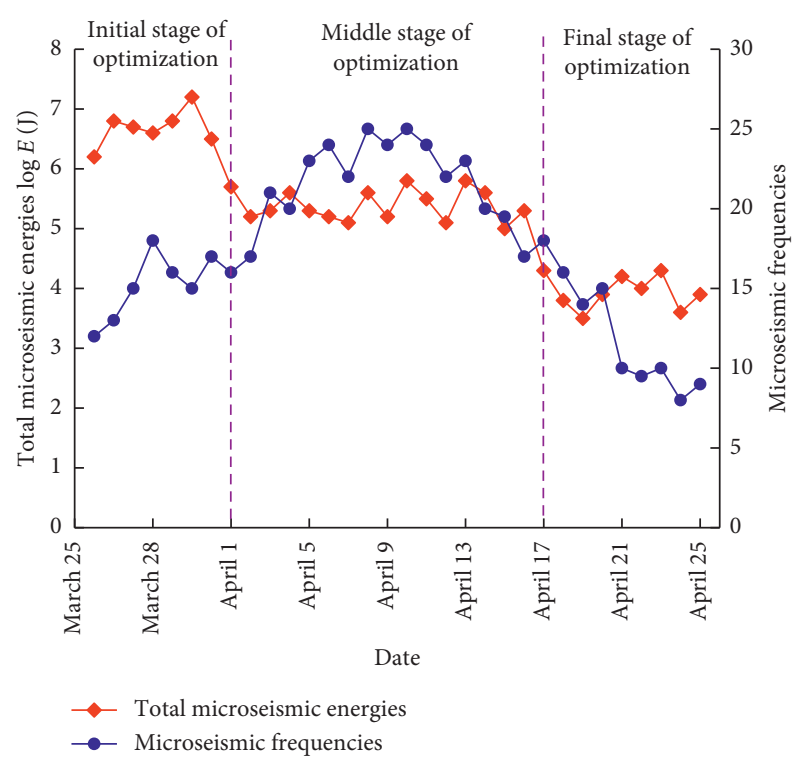

Figure 15: Microseismic monitoring results after parameter optimisation for deep-hole presplit blasting.

masses, where the triangular coal mass is in a limit equilibrium state while the peak mining-induced stress lies in the deeper part of the load-bearing coal mass. The stress distributions of abutment pressures in the limit equilibrium zone of a steeply inclined coal mass are determined and the side abutment pressure near the roof and floor under horizontal section of SICSs is asymmetrically distributed along the vertical direction in which the peak side abutment pressure on the side of the roof is closer to the working face. Therefore, this point is taken as the source of static loads for coal bursts in working faces.

(2) When the superimposed dynamic load caused by hanging roof breaking and the high static load borne by a coal mass exceeds the critical load inducing a coal bursts, coal bursts will occur. Furthermore, when the superimposed additional dynamic load induced by coal bursts and initial static load on the supports exceeds their bearing capacity, the supports collapse and eventually cause dynamic failure of the working face.

(3) The coal bursts in working faces for horizontal sections of SICSs can be effectively prevented by using deep-hole presplit blasting, destress blasting in coal masses, and parameter optimisation in the design of hydraulic supports, all of which show favourable preventative effects.

\section{Data Availability}

The in-situ measurement data used to support the findings of this study are available from the corresponding author upon request.

\section{Conflicts of Interest}

The authors declare that there are no conflicts of interest regarding the publication of this paper.

\section{Acknowledgments}

Financial support for this work provided by the State Key Research Development Program of China (Grant no. 2016YFC0801403), the National Natural Science Foundation of China (Grant no. 51504248), the State Key Laboratory of Coal Resources and Safe Mining, CUMT (Grant no. SKLCRSM16X05), the Central Universities (Grant no. 2017QNA27), and the Project of PADD funded by the Priority Academic Programme Development of Jiangsu Higher Education Instruction (no. SZBF2011-6-B35) is gratefully acknowledged.

\section{References}

[1] Y. Deng and S. Wang, "Feasibility analysis of gob-side entry retaining on a working face in a steep coal seam," International Journal of Mining Science and Technology, vol. 24, no. 4, pp. 499-503, 2014.

[2] Y. P. Wu, K. Z. Liu, D. F. Yun, and P. S. Xie, "Research progress on the safe and efficient mining technology of steeply dipping seam," Journal of China Coal Society, vol. 39, no. 8, pp. 1611-1618, 2014.

[3] J. A. Wang and J. L. Jiao, "Criteria of support stability in mining of steeply inclined thick coal seam," International Journal of Rock Mechanics and Mining Sciences, vol. 82, pp. 22-35, 2016.

[4] X. P. Lai, P. F. Shan, J. T. Cao, F. Cui, and H. Sun, "Simulation of asymmetric destabilization of mine-void rock masses using a large 3D physical model," Rock Mechanics and Rock Engineering, vol. 49, no. 2, pp. 487-502, 2015.

[5] Y. Zhang, B. Zhang, and L. Li, "Study on the effect of roof fracture development on gas drainage in steep fullmechanized caving mining," Journal of Mining and Safety Engineering, vol. 31, no. 5, pp. 809-813, 2014.

[6] L. Dou, W. Cai, A. Cao, and W. Guo, "Comprehensive early warning of rock burst utilizing microseismic multi-parameter indices," International Journal of Mining Science and Technology, vol. 28, no. 5, pp. 767-774, 2018.

[7] G. A. Zhu, L. M. Dou, C. B. Wang, J. Li, W. Cai, and Z. W. Ding, "Numerical investigations on evolution characteristics of overlying strata and distribution of static and dynamic load in an island coal panel," Arabian Journal of Geosciences, vol. 10, no. 24, p. 549, 2017.

[8] W. J. Ju and W. Z. Li, "Fracture mechanical model of main roof along inclined for full-mechanized top-coal caving in steep extra-thick coalseam," Journal of China Coal Society, vol. 33, no. 6, pp. 606-608, 2008.

[9] X. P. Lai, Y. R. Yang, and N. B. Wang, "Comprehensive analysis method of dynamic instability spatial-temporal evolution characteristic of steeply inclined coal-rock mass," Chinese Journal of Rock Mechanics and Engineering, vol. 37, no. 3, pp. 583-592, 2018.

[10] N. B. Wang, N. Zhang, and F. Cui, "Characteristics of stope migration and roadway surrounding rock fracture for fullymechanized top-coal caving face in steeply dipping and extra thick coal seam," Journal of China Coal Society, vol. 38, no. 8, pp. 1312-1318, 2013.

[11] X. Li, Z. Wang, and J. Zhang, "Stability of roof structure and its control in steeply inclined coal seams," International Journal of Mining Science and Technology, vol. 27, no. 2, pp. 359-364, 2017. 
[12] M. G. Qian, P. W. Shi, and J. L. Xu, Mining Pressure and Strata Control, China University of Mining and Technology Press, Xuzhou, China, 2010.

[13] L. M. Dou, Z. L. Mu, Z. L. Li, A. Y. Cao, and S. Y. Gong, "Research progress of monitoring, forecasting, and prevention of rockburst in underground coal mining in China," International Journal of Coal Science \& Technology, vol. 1, no. 3, pp. 278-288, 2014.

[14] Z. L. Li, X. Q. He, and L. M. Dou, "Control measures and practice for rock burst induced by overburden fracture in topcoal caving mining," Journal of China University of Mining \& Technology, vol. 47, no. 1, pp. 162-171, 2018.

[15] F. Cui, X. P. Lai, and J. T. Cao, "Mining disturbance of horizontal section full-mechanized caving face in steeply inclined coal seam," Journal of Mining and Safety Engineering, vol. 32, no. 4, pp. 610-616, 2015.

[16] X. P. Lai, Y. R. Yang, and J. Q. Chen, "Control of dynamic hazards induced by mining stress distortion in extremely steep and thick coal seams," Journal of China Coal Society, vol. 41, no. 7, pp. 1610-1616, 2016.

[17] J. J. Liu, "Analysis and calculation on parameters of stress distribution of the front coal mining face," Journal of China Coal Society, vol. 33, no. 7, pp. 743-747, 2008.

[18] W. J. Ju, Study on Reasons of Rock Burst in Roadway and Prevention Technology of Steeply-Inclined and Extremely Thick Coal Seam with Horizontally Slicing Way, Beijing Jiaotong University, Beijing, China, 2009.

[19] J. W. Zhang, The Fracture Mechanism of Main Roof Statum and Strong Mine Pressure Control Method in Longwall Mining of Steeply Inclined Coal Seam in Wang Jia-Shan Colliery, University of Science and Technology Beijing, Beijing, China, 2015.

[20] J. He, Research of Mining Dynamic Loading Effect and Its Induced Rock Burst in Coal Mine, China University of Mining and Technology, Xuzhou, China, 2013.

[21] J. He, L. M. Dou, W. Cai, Z. L. Li, and Y. L. Ding, "In situ test study of characteristics of coal mining dynamic load," Shock and Vibration, vol. 2015, p. 8, 2015.

[22] A. Y. Cao, L. M. Dou, R. L. Yan et al., "Classification of microseismic events in high stress zone," Mining Science and Technology (China), vol. 19, no. 6, pp. 718-723, 2009.

[23] L. M. Dou, C. G. Zhao, and S. G. Yang, Prevention and Control of Rock Burst in Coal Mine, China University of Mining and Technology Press, Xuzhou, China, 2006.

[24] Z. Yang, C. Liu, S. Tang, L. Dou, and J. Cao, "Rock burst mechanism analysis in an advanced segment of gob-side entry under different dip angles of the seam and prevention technology," International Journal of Mining Science and Technology, vol. 28, no. 6, pp. 891-899, 2018.

[25] M. S. Gao, Study on the Strong-Soft-Strong Structure Control Mechanism of Roadway Subjected to Rock Burst, China University of Mining and Technology, Xuzhou, China, 2006.

[26] L. M. Dou, C. P. Lu, and Z. L. Mu, "Intensity weakening theory for rockburst and its application," Journal of China Coal Society, vol. 30, no. 5, pp. 690-694, 2005.

[27] L. M. Dou, Z. L. Li, and X. Q. He, "Principle of rockburst control by weakening static and dynamic loading using topcoal caving in the mining of thick coal seams," Journal of China University of Mining \& Technology, vol. 47, no. 2, pp. 221-230, 2018.

[28] G. A. Zhu, Overstress Effect of Rock and Coal and Study on Mechanism of Overall Rock Burst Instability on Island Coal
Panel in Underground Deep Mining, China University of Mining and Technology, Xuzhou, China, 2017.

[29] L. M. Dou and X. Q. He, Theory and Technology of Rock Burst Prevention, China University of Mining and Technology Press, Xuzhou, China, 2001. 


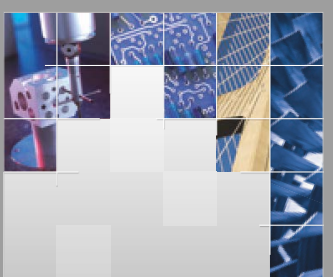

\section{Enfincering}
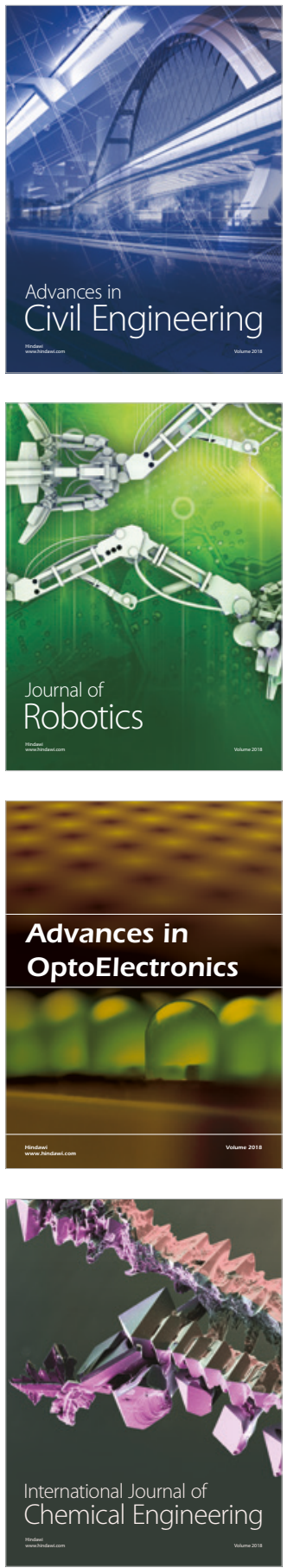

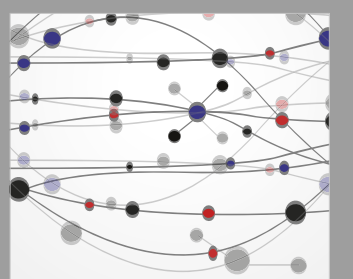

\section{Rotating \\ Machinery}

The Scientific World Journal

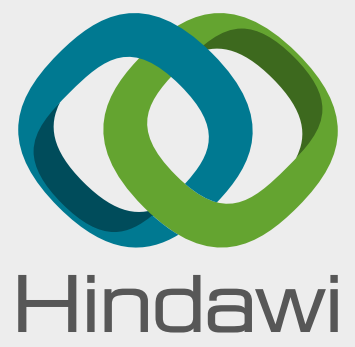

Submit your manuscripts at

www.hindawi.com
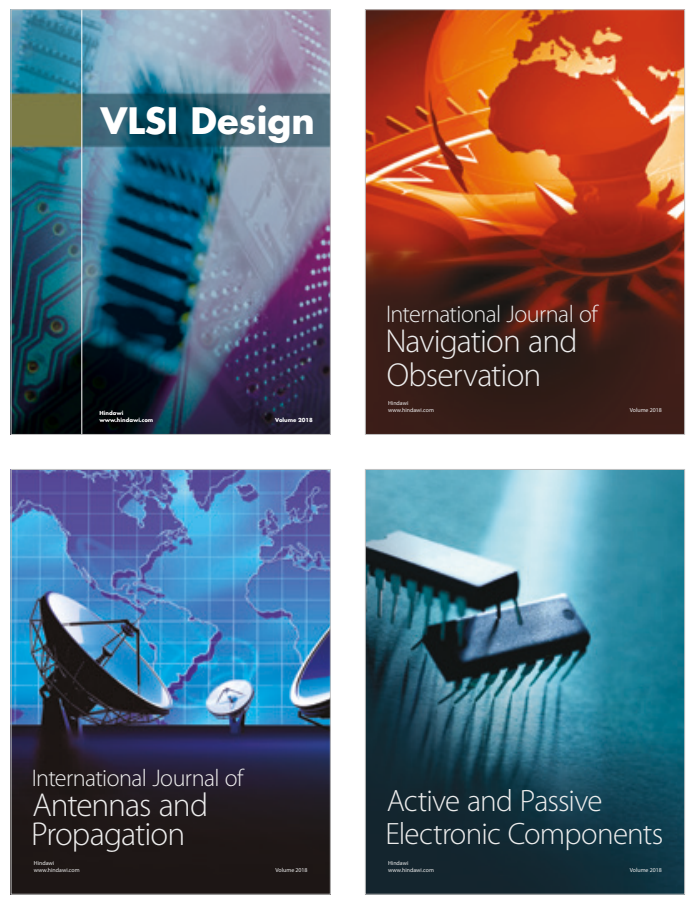
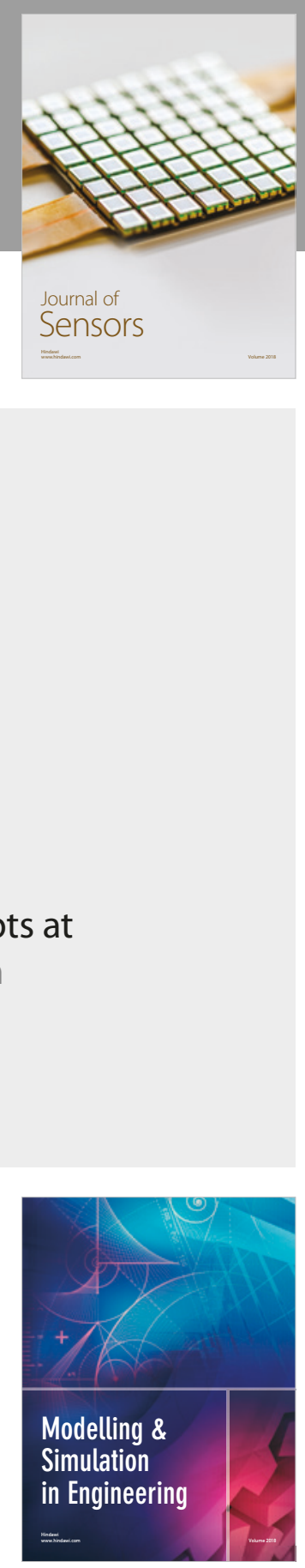

\section{Advances \\ Multimedia}
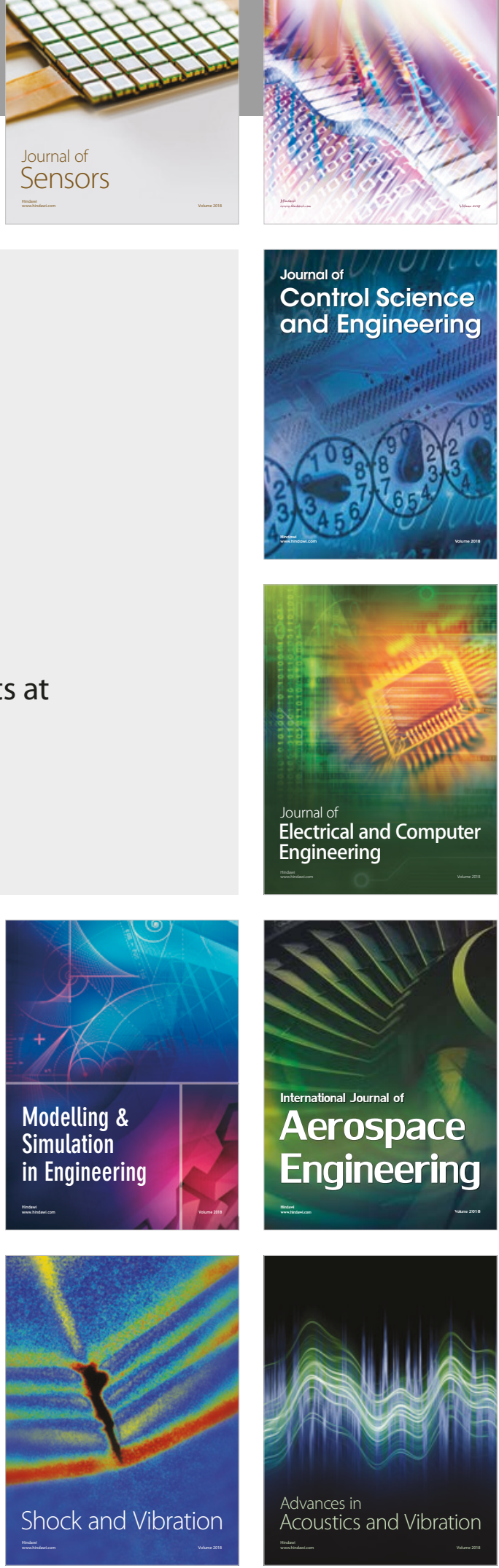